\title{
Costa Rica: La abolición del ejército y la construcción de la paz regional
}

\author{
Mercedes MuÑoz G. \\ Universidad de Costa Rica \\ mercedes.munoz@ucr.ac.cr
}

Recibido: 24 de septiembre de 2014

Aceptado: 4 de octubre de 2014

\begin{abstract}
Resumen
Este artículo da cuenta de dos hechos históricos interesantes: la declinación y la abolición del ejército en Costa Rica. Además explica la no menos sorprendente supervivencia de este experimento político hasta hoy. Ambos hechos se analizan en relación con el marco geoestratégico imperante en América Central durante los últimos cien años, esto es, desde la apertura del Canal de Panamá hasta más allá de la conclusión de la Guerra Fría.
\end{abstract}

Palabras claves: Estado-ejército; intereses geoestratégicos; micro-región canalera; guerra-paz.

\section{Costa Rica: The abolition of the army and the construction of peace in the Central American Region}

\begin{abstract}
This article deals with two interesting historical facts: the declining process of the Costa Rican Army and its subsequent abolition together with the amazing survival of this political experiment nowadays. Both facts are analyzed within the political situation of the Central American Isthmus during the last one hundred years, that is, since the opening of the Panama Canal and beyond the end of the cold war.
\end{abstract}

Key words: state-army-micro canal region-geopolitics-war-peace.

\section{Referencia normalizada}

Muñoz G., M. (2014) Costa Rica: La abolición del ejército y la construcción de la paz regional. Historia y Comunicación Social. Vol. 19. Páginas 375-388.

Sumario: 1. Introducción 2. Estado de la cuestión. 3. La Gran Guerra: la micro-región canalera y declinación del Ejército 1914-1923. 3.1. El impacto sobre la micro-región canalera. 3.2. Hacia la declinación del ejército. 4. Abolición del Ejército en un contexto bélico. 1940-1949. 4.1. La Segunda Guerra Mundial y reforzamiento de la Seguridad. 4.2. La abolición del Ejército. 5. Seguridad y soberanía 19501989. 6. Conclusiones. 7. Referencias bibliográficas. 


\section{Introducción}

El ejército ha sido considerado como una expresión básica del poder estatal. Desde la publicación de El Príncipe por Maquiavelo, la ciencia política sostiene que no puede existir un Estado sin un cuerpo profesional armado que garantice su defensa exterior e interior. Ni siquiera la autoridad de Kant logró debilitar esta convicción cuando hace más de doscientos años proclamó, en la Paz Perpetua, la necesidad de hacer desaparecer por completo los ejércitos permanentes, porque constituyen una amenaza constante de guerra para los demás Estados.

¿Cómo explicar entonces la proscripción del ejército de un país pequeño como Costa Rica, en un momento crítico de su historia y en una región no caracterizada precisamente por su pacifismo y estabilidad política? Será posible que este experimento político -incómodo para la teoría del Estado- se explique mejor por medio del siguiente y paradójico hallazgo: "porque le tememos a otros [Estados] creamos instituciones de violencia [ejércitos] para protegernos, pero luego le tememos a la misma institución [ejército] que creamos para ello" (Feaver, 1997: 68).

Los politólogos utilizan este hallazgo para justificar su interés en las relaciones cívico-militares y, en última instancia, para dar cuenta de la expansión del sistema democrático. Se supone que mientras más democrático es un Estado, mayor es el control civil ejercido sobre los militares y, por consiguiente, menor la posibilidad de que éstos utilicen su poder para ejercer violencia ilegítima contra su población $u$ otros Estados. El punto débil de esta formulación es que olvida que el sistema internacional no es democrático y que históricamente los países pequeños tienen sobradas razones para temer a los ejércitos de las potencias hegemónicas y pocos recursos para oponerse a los designios geopolíticos de estas últimas.

Con el propósito de apreciar cómo opera lo geopolítico en el caso costarricense se emplea el concepto de micro-región canalera. La introducción de este concepto permite afirmar, que dada la existencia del Canal de Panamá y del Proyecto de Canal en Nicaragua, ambos bajo bandera norteamericana, la existencia de fuerzas armadas en Panamá y Nicaragua obligaría al brazo armado costarricense a plantearse las correspondientes "hipótesis de guerra"; así la presencia de tropas norteamericanas en ambos países durante parte del periodo, en que existe el ejército, impide este rutinario juego de guerra castrense.

De hecho, como este último factor resulta ser el más fuerte, toda vez que los ejércitos nacionales son sólo partes del sistema global de defensa de los Estados Unidos de América, en la práctica las dos únicas hipótesis de guerra probables para Costa Rica llegan a ser "imposibles" y por tanto superfluo su brazo armado.

La introducción del concepto de micro-región canalera en este trabajo permite el empleo del método comparativo, que resulta ser el más idóneo para explicar las peculiaridades del Estado costarricense frente a los dos Estados fronterizos vecinos para: comprender la importancia de los intereses geoestratégicos de los Estados Unidos de América en la subregión; establecer la relación entre la política exterior de los 
Estados Unidos hacia Costa Rica, y los efectos que ésta tiene sobre la remodelación del aparato represivo costarricense. Situación que en lo esencial se manifiesta en el debilitamiento de la función de seguridad interna, en la inhibición de la función de seguridad externa del ejército y en su progresiva metamorfosis en policía.

Tres son los focos de interés de este trabajo: la declinación del ejército, es decir, el debilitamiento de su poder político, su abolición, esto es, la desmilitarización del Estado, y finalmente, el dilema de seguridad o soberanía en el contexto de la crisis centroamericana de la década de 1980.

\section{Estado de la cuestión}

Es reconocido que no hay ningún otro continente donde la presencia de los militares haya sido tan marcada como en América Latina. También, hay quienes sostienen que con la sola excepción de Costa Rica y México, el significado real del aparato militar ha sido básicamente político (Kruijt y Torres-Rivas, 1991: 9). Esto explica el interés de las ciencias sociales por abordar el tema de las relaciones cívico-militares comparadas, ya que se admite que la institución militar se cuenta entre las instituciones menos democráticas de la experiencia humana (Kohn, 1997: 39).

En relación con el caso costarricense, tres obras nos parecen de interés para formarse una idea del estado del arte. En primer lugar, desde la perspectiva sociológica, resulta conveniente consultar el libro Orden y Progreso. La formación del Estado nacional en Costa Rica (Vega, 1981), donde se hace una interpretación del desarrollo histórico costarricense y se encuentran análisis fragmentarios de la institución militar.

Este ensayo destaca por la audacia de sus interpretaciones y porque el autor presenta, resume y racionaliza una visión idealizada y "civilista" del desarrollo histórico de Costa Rica, exalta la existencia de métodos consensuales de dominación y tiende a dejar en el claroscuro el rol jugado por el ejército.

En segundo lugar, desde la perspectiva de la ciencia política, resulta imprescindible la lectura del artículo: El Control Civil en Democracias Pequeñas. La Contribución de las Ciencias Políticas (Feaver, 1997: 67). En este sugerente ensayo su autor pasa revista a las contribuciones de esta especialidad al tema de las relaciones cívico-militares y se pregunta si el experimento político de Costa Rica puede ser replicado por otras democracias pequeñas.

Según este politólogo norteamericano, la "opción costarricense" requiere de confianza en los acuerdos de seguridad colectiva o en la bona fides de una gran potencia amiga. También requiere que el Estado pequeño esté dispuesto a sacrificar parte de su soberanía. Pero aun dándose estas condiciones, la predicción con la que concluye dista mucho de ser optimista: "Esta opción es quizás una meta plausible para América Central en el mediano plazo, pero ciertamente no es creíble en el corto plazo, como tampoco es creíble en ninguna otra parte en el futuro próximo" (Feaver, Ibid). 
La generalización contenida en esta predicción no deja de ser sorprendente, habida cuenta que en 1990, siete años antes de la publicación de Feaver, un segundo Estado de la micro-región canalera, Panamá, abolió por decreto su ejército, ya desmantelado el año anterior y no precisamente por la bona fides de una potencia amiga. Pero como, por otra parte, el texto de Feaver explícitamente hace alusión a tal realidad, su predicción debe interpretarse como el reconocimiento de lo que ya ocurrió en la micro-región canalera, podría ocurrir en el mediano plazo sólo en el resto de América Central.

En tercer lugar, desde la perspectiva de la historia, puede consultarse: El Estado y la abolición del ejército. 1914-1949 (Muñoz, 1990), trabajo de nuestra autoría que sirve de base a este artículo, donde se cuestiona la cronología utilizada por Vega Carballo para dar cuenta de la declinación del ejército. Se rechazan las relaciones causales simplistas para explicar el fenómeno de la abolición y se compara la forma en que los tres Estados de la micro-región canalera enfrentan el dilema de seguridad o soberanía ante los cambios experimentados por el marco geopolítico impuesto por los Estados Unidos de América.

También resulta de utilidad para ampliar este último tópico en el contexto de la crisis centroamericana de la década de 1980, el artículo El dilema del Estado costarricense: seguridad nacional o soberanía, escrito en coautoría con Rodia Romero (Muñoz y Romero, 1991).

Valga además, señalar que, una vasta bibliografía levantada por el Sistema Nacional de Bibliotecas (Costa Rica, Ministerio de Cultura, Juventud y Deportes, 2004), puede ser muy útil para ampliar la visión aquí expuesta y otros aspectos vinculados con el tema de la abolición del ejército.

\section{La Gran Guerra: la micro-región canalera y declinación del Ejército. 1914- 1923}

\subsection{El impacto sobre la micro-región canalera}

El conflicto mundial trajo aparejada una crisis económica y social de grandes dimensiones: hambre y miseria se extendieron por varios años y afectaron a los más débiles. De ahí, la importancia de iniciativas previas para promover la lactancia materna (Botey, 2012: 31).

Ese año marcó también el comienzo de la Administración de Alfredo González Flores, a quien le correspondió tomar una serie de medidas para enfrentar la crisis, que a la postre, entre otras razones, provocaron un golpe de estado y la instauración en 1917 de una dictadura al mando del General Federico Tinoco y de su hermano, el General Joaquín Tinoco, Ministro de Guerra y Marina.

El Canal de Panamá, obra maestra de la tecnología de su época, estaba listo para ser inaugurado en agosto de 1914, cuando estalló la Primera Gran Guerra. Los planes 
fueron desestimados al calor de las amenazas sobre el paso interoceánico hacia donde se extendió la frontera sur de los Estados Unidos de América.

Los nuevos linderos dieron a los países subsumidos en ella una importancia geoestratégica desconocida. Inclusive Costa Rica pasó a ser observada como margen canalera. A raíz de la Guerra, el factor geopolítico se potenció y una serie de medidas se dispusieron para preservar la estabilidad política en las inmediaciones del Canal (Muñoz, 1990: 11).

\subsection{Hacia la declinación del Ejército}

Federico Tinoco, por más esfuerzos propios y de representantes del capital norteamericano, que se solidarizaron con las gestiones para obtener el reconocimiento del gobierno de los Estados Unidos de América, constató el fracaso de tales gestiones.

No solamente, no obtuvo el reconocimiento, sino que el país sufrió los efectos del bloqueo económico. Se presentó además, una clara amenaza de intervención militar, cuando un buque de guerra con bandera norteamericana fue desplazado al Puerto de Limón (Murillo, 1981: 161).

Amparado en la fuerza del otrora exitoso ejército costarricense que contribuyó con la formación del Estado y que libró insignes batallas en la Guerra contra los filibusteros en el siglo XIX, ahora reprimía los movimientos en su contra. Estos se incrementaban día a día en la capital y en la zona limítrofe con Nicaragua, desde donde se organizó la resistencia armada contra el régimen con la ayuda de elementos nicaragüenses.

Aislado el General Tinoco desiste de continuar en el ejercicio del poder en 1919 y se va del país. Después de dos fallidos nombramientos de sucesores y bajo la mira de los estadounidenses se convoca a elecciones. Julio Acosta resulta ganador del proceso electoral, asume el poder y cumple con los requisitos para ser reconocido por los norteamericanos.

Queda claro, en adelante a los gobernantes, que en las inmediaciones del Canal de Panamá no se permitiría ningún movimiento desestabilizador y que la institución militar costarricense no será más la encargada de mantener el orden interno.

La función de defensa externa del ejército también se verá limitada cuando a raíz de las diferencias limítrofes entre Costa Rica y Panamá se movilizan las fuerzas armadas a la zona fronteriza entre ambos países y la acción es interrumpida por una autoridad norteamericana.

El retiro al cual son obligadas las fuerzas armadas antes del inicio del enfrentamiento los desalienta. El sometimiento a la orden recibida era comprensible en el caso de las fuerzas panameñas, dada la condición de cuasi- protectorado que ostentaba ese Estado, pero no en el caso de las fuerzas costarricenses.

Con gran claridad años después un ex presidente de Costa Rica, reconoció que vencer a Panamá o que Panamá nos venciera es cuestión de pueblos que disputan por 
sus derechos, pero plegarse a la voluntad de los más fuertes, ya es cuestión de bajar penosamente la frente ante la fuerza (Jiménez, 1931: 6).

La declinación del ejército no se hizo esperar después de estos eventos, en su lugar la Policía de Orden y Seguridad empezó a ocupar un papel más relevante a partir de entonces. Es notorio el cambio hacia la represión policial para contrarrestar los conflictos agrarios y los movimientos urbanos (Muñoz, 1990: 129).

En tanto, los EE.UU en la posguerra logra consolidar sus intereses en Centroamérica y para eso impulsa la firma de Tratados de Paz y Amistad en 1923 y la firma de Acuerdos para la reducción de armas, donde se fijó el número de efectivos para cada uno de los ejércitos de estos países y se estimula la creación de guardias nacionales en reemplazo de los viejos ejércitos. Panamá estaba excluida de estos acuerdos.

\section{La Abolición del Ejército en un contexto bélico. 1940-1949}

\subsection{La Segunda Guerra Mundial y reforzamiento de la Seguridad}

Los Estados Unidos de América reforzó aún más la seguridad continental, promovió la firma de acuerdos militares con distintos países de América Latina con el fin de crear un anillo de seguridad y lograr desplazar a los instructores militares de las naciones europeas.

El Canal de Panamá, objetivo geoestratégico de primer orden, cuenta para 1940 con una cantidad importante de bases militares, desde donde se dirigen operaciones hacia diferentes lugares. Los otros dos países que forman parte de la micro-región canalera ya contaban con elementos suficientes para garantizar la estabilidad y el control del territorio.

En el caso de Costa Rica el Presidente Rafael Ángel Calderón Guardia (19401944) se puso a disposición de los norteamericanos. Firmó con ellos un Convenio Militar en 1940, mediante el cual, entre otros acuerdos, se organizó la Unidad Móvil, un cuerpo de 200 hombres para mantener el orden interno y se autorizó la instalación de baterías antiaéreas en territorio costarricense (Muñoz, 1990: 138).

La Guerra puso en evidencia una cruda realidad, el deterioro de las condiciones económicas y sociales de las grandes mayorías. La aprobación de la Legislación Social y del Código de Trabajo fue un respiro para muchos, aunque su aplicación no se dio de inmediato.

Esa polémica conquista social y la polarización ideológica del país, inician con la creación del Partido Comunista en 1931 y constituyen hitos de gran relevancia en el devenir de la década de 1940 (Molina, 2007: 138-139).

Las aspiraciones políticas de distintos bandos aliados para alcanzar o mantener el poder por la vía electoral, se dan en el marco de campañas políticas que reprodu- 
cen las contradicciones entre las posiciones ideológicas y las alianzas del escenario mundial. Primero en la lucha contra el fascismo y luego contra el comunismo.

El mundo bipolar de la posguerra trajo la ruptura de las alianzas controversiales creadas entre los países beligerantes para repeler a los nazis. Tomando en consideración que en Costa Rica se mantuvo la vieja alianza entre el Partido Republicano, la Iglesia Católica y el Partido Vanguardia Popular, se impulsa una fuerte campaña anticomunista.

El partido de oposición en las elecciones de 1948, el Unión Nacional, con Otilio Ulate como candidato, se inscribe dentro de esa corriente anticomunista. Ulate dirige su campaña contra el candidato del oficialismo, el Dr. Rafael Ángel Calderón Guardia del Partido Republicano Nacional.

Los polémicos resultados electorales, las anomalías que se presentan y la decisión de anular las elecciones, entre otros hechos, fueron razones suficientes para que la oposición diera por agotada la vía electoral, como fórmula para alcanzar el poder y un sector de ella se levante en armas (Molina, 1999: 189).

José Figueres Ferrer, el líder, es un empresario con aspiraciones políticas y seguidor del partido de oposición, quien ya había optado por organizar el llamado Ejército de Liberación Nacional (ELN). Él contó para ese fin con el apoyo de exilados políticos de distintos países del Caribe y armas provenientes de Guatemala. Dispuesto a defender el derecho al sufragio se levanta en armas el 12 de marzo de 1948 en el sur del territorio, cerca de donde los norteamericanos construyen la carretera interamericana.

Las fuerzas del gobierno, carentes de un espíritu de corps y de unidad en el mando, estaban integradas por hombres que obedecían a distintos líderes para enfrentar al enemigo. Son derrotadas y el ejército vencedor se impone como fuerza oficial. Una Junta de Gobierno, presidida por José Figueres, asume los destinos de la Segunda República, anunciada desde años atrás por él mismo.

La situación después del conflicto armado, pese a los acuerdos entre vencedores y vencidos, es compleja. Hay diferencias entre los integrantes de la Junta con respecto a los compromisos adquiridos por Figueres con los extranjeros; cuentas por saldar, indemnizaciones, recompensas que se otorgan y una economía con rentas deficitarias.

La Junta era en esencia un gobierno de facto que no contó con el aval norteamericano para adquirir armas y municiones. Por tanto, el ejército no estaba en capacidad para cumplir con el compromiso adquirido por el líder con los integrantes de la Legión del Caribe y un grupo de nicaragüenses colaboradores del ELN, quienes esperaban continuar la lucha armada para derrocar a las dictaduras del Caribe, empezando por Nicaragua.

La amenaza constante de una invasión procedente desde ese país, hacia donde se habían dirigido los vencidos, ponía en riesgo el control del poder por parte de la Junta Fundadora de la Segunda República y comprometía, no sólo la estabilidad del país, 
sino la de Nicaragua, donde el régimen somocista era un aliado fiel de los intereses defendidos por la potencia.

\subsection{La abolición del Ejército}

¿Por qué entonces el acto simbólico del $1^{\circ}$ de diciembre de 1948 anunciando el fin del ejército en esas circunstancias?

Este acto simbólico se atribuye a los cálculos políticos de Figueres, a quien le interesa primero, afianzarse en el poder y segundo, evitar o atenuar medidas en su contra por parte del Sistema Interamericano, liderado por los norteamericanos. El gobernante contaba con un ejército, pero éste tenía una capacidad de fuego limitada y, por otro lado, estaba en manos de Edgar Cardona, Ministro de Seguridad de la Junta de gobierno quien se oponía a los compromisos de Figueres con los extranjeros.

Los acuerdos suscritos en el seno del Sistema Interamericano, que dieron paso al Tratado de Asistencia Recíproca (TIAR) en 1947 y a la Organización de Estados Americanos (OEA) en 1948, eran conocidos por Figueres. Los invoca cuando el 10 de diciembre se produce la invasión liderada por Calderón Guardia, con el apoyo de la Guardia Nacional de Nicaragua. Solicita ayuda a la OEA y aduce que un país desarmado no puede ser invadido.

Los resultados de la gestión ante los organismos del Sistema Interamericano son favorables a los cálculos políticos de Figueres en dos sentidos: de partida porque él logra mantenerse en el poder y, por consiguiente, es una especie de reconocimiento tácito dado por la OEA a la Junta.

Luego, porque la Comisión Investigadora creada por la OEA señala que, tanto en Nicaragua como en Costa Rica existen grupos armados que atentan contra la estabilidad de ambos gobiernos, por lo que les solicita su desarticulación y la firma de un Convenio de Paz y Amistad.

Este pronunciamiento resuelve, a favor de Figueres, el compromiso adquirido con la Legión Caribe y con los nicaragüenses para dar seguimiento a la lucha armada en la Región del Caribe.

Mientras se mantuvo la misión de la OEA, el ejército costarricense se había desplazado hacia el noroeste del país, al mando del Jefe del Estado Mayor Edgar Cardona, para repeler a los invasores y en defensa de la seguridad exterior. En otras palabras el anuncio del fin del ejército había sido un acto simbólico y no real.

Otra prueba de que el brazo armado de la Junta seguía en funciones, la dio el Coronel Cardona, Ministro de Seguridad, cuando al regreso a la capital, a principios del mes de abril de 1949, se hizo fuerte con un grupo de oficiales en el Cuartel de Artillería, en un intento por derrocar a Figueres.

"El Cardonazo" fracasó por dos razones: no tuvo el respaldo político necesario, y además, porque el Presidente de la Junta contó con el apoyo de Frank Marshall 
Jiménez, acérrimo anticomunista, al igual que Cardona, y uno de los hombres que conservó armas del pasado conflicto bélico.

Figueres tomó tres medidas en relación con este acontecimiento: primero, dio de baja a los amotinados; segundo, nombró un Tribunal Militar para juzgarlos en primera instancia, para que luego la causa fuera dictaminada en los tribunales comunes; y tercero, mediante el decreto del 12 de mayo de 1949 crea la Guardia Civil de Costa Rica, integrada por hombres de su confianza procedentes, en su gran mayoría, del Ejército de Liberación Nacional.

En tanto estas acciones armadas y diplomáticas ocupaban la agenda diaria de la Junta, otras medidas se ponían en marcha para volver a la legitimidad democrática del país. A esto se dedicaba la Asamblea Constituyente que tenía entre manos la reorganización del Estado en el marco de la Guerra Fría. Uno de los puntos a tratar fue el de la inclusión de un artículo referente al Ejército costarricense.

La decisión sin controversias fue clara y consta en el artículo 12 de la Constitución de 1949, vigente hasta hoy. En éste se acordó proscribir el Ejército como institución permanente y se prevé que, para la vigilancia y conservación del orden público se dispondrá de fuerzas de policía. Otro aspecto que se estableció, en ese artículo, es que sólo por convenio continental o para la defensa nacional podrán organizarse fuerzas militares y que éstas quedan subordinadas al poder civil, no pueden deliberar, ni hacer manifestaciones o declaraciones en forma individual o colectiva (Costa Rica, 1949:773).

De esta manera se establecen las bases legales de la construcción de una sociedad civilista y un estado social de derecho que privilegia la inversión en salud, educación y vivienda por encima de lo militar.

De lo anterior se desprende que los caminos hacia una paz duradera en el país, son diferentes en relación con lo que acontece en otras partes de la Región a mediados del siglo XX.

\section{Seguridad y soberanía. 1950-1989}

Los problemas de seguridad de la democracia desarmada costarricense siguen teniendo que ver con el anticomunismo y con las violaciones a la frontera Norte por fuerzas irregulares.

En relación con la amenaza del comunismo éstas se enfrentaron desde la Constitución de 1949, donde quedó definido el carácter ilegal del Partido Comunista en el párrafo segundo del artículo 98.

No fue, sino a inicios de la década de 1970 que se suprimió dicho párrafo y los llamados partidos de izquierda pudieron participar en los comicios electorales. Más la amenaza comunista acompañó todo el período hasta la caída del mundo socialista 
en 1989. La ideologización de las fuerzas policiales bajo la bandera del anticomunismo, primero, y luego el brazo armado del Movimiento Costa Rica Libre (MCRL), un grupo paramilitar organizado en 1961, se complementaron para asegurar y mantener el orden interno de esta democracia liberal.

El cuadro siguiente presenta un panorama de las amenazas externas a la seguridad y la soberanía. Éstas en general tienen como escenario la zona fronteriza con Nicaragua. Las iniciativas gubernamentales para resolverlas siguen en principio, la lógica de solicitar al organismo insignia del Sistema Interamericano, la OEA, su intervención y la aplicación del Pacto de Río. Estas instancias sólo respondieron para la situación presentada en 1955. En la segunda ocasión no hubo respuesta de la OEA y ante la última las medidas se apartaron de esa lógica.

Amenazas a la Seguridad y la Soberanía del Estado Costarricense. 1955-1989

\begin{tabular}{|c|l|l|}
\hline Año & \multicolumn{1}{|c|}{ Evento } & \multicolumn{1}{c|}{ Medidas gubernamentales } \\
\hline 1955 & $\begin{array}{l}\text { Invasión desde Nicaragua por el ex } \\
\text { presidente Calderón Guardia, con apoyo de } \\
\text { la Guardia Nacional nicaragüense. }\end{array}$ & $\begin{array}{l}\text { Solicitud ante la OEA y aplicación del } \\
\text { TIAR. }\end{array}$ \\
\hline 1979 & $\begin{array}{l}\text { Agresiones de la Guardia Nacional de } \\
\text { Nicaragua en zona fronteriza del norte }\end{array}$ & $\begin{array}{l}\text { Retiro de línea fronteriza y petición de } \\
\text { ayuda a gobiernos amigos. }\end{array}$ \\
\hline $\begin{array}{c}\text { Década } \\
1980\end{array}$ & $\begin{array}{l}\text { Impacto de Guerra de Baja Intensidad } \\
\text { (GBI) y de grupos armados en frontera } \\
\text { norte. }\end{array}$ & $\begin{array}{l}\text { Proclama de Neutralidad y Plan Regional } \\
\text { de Paz de Esquipulas. }\end{array}$ \\
\hline
\end{tabular}

Fuente. Elaboración propia.

Tomando en consideración la importancia de dejar claras las razones que llevaron a la superación del estrecho concepto de paz, entendido como ausencia de guerra, se dedica atención a lo que sucede a mediados de la década de 1980, en el marco de la GBI que se libra en Centro América.

Es manifiesto el interés de los norteamericanos de dotar de armas a los grupos opositores al régimen sandinista; en Costa Rica involucrar a los gobiernos de Luis Alberto Monge y de Oscar Arias en la caída de ese régimen, y por tanto en el fracaso de la Revolución de orientación socialista.

Por otra parte, debe tenerse en cuenta la particular y compleja situación que vivían los costarricenses a raíz de la aguda crisis económica y la necesidad de ayuda externa para sortearla. Ésta se recibió precisamente de la Agencia Internacional de Desarrollo (AID) (Muñoz y Romero, 1991: 159).

Ante las presiones, se acudió a exaltar el desarme en los foros internacionales y también en manifestaciones callejeras haciendo ver la vocación por la paz del pueblo y del gobierno. Un logró muy significativo en la búsqueda de fórmulas conducentes a poner fin a la guerra en la Región, fue el apoyo del llamado Grupo de Contadora, integrado por México, Panamá y Venezuela y luego ampliado a cuatro países más, todos de América del Sur. 
Países amigos de Europa respaldaron los esfuerzos que se emprendieron. Uno de los resultados más inesperados y con clara influencia europea, lo constituyó la Declaración de Neutralidad Perpetua y no Armada, dada durante la Administración de Monge Álvarez.

El país mantuvo una autonomía relativa para emprender e inclusive liderar, el proceso de negociación de la paz que pone fin al último episodio de la Guerra Fría en C.A. El papel beligerante de la Administración Arias y de un grupo de asesores fue fundamental.

El Acuerdo de Paz de Esquipulas, firmado en 1987 se impuso sobre otras iniciativas, éste tuvo el mérito de ser un acuerdo regional para una paz duradera y con una visión que va más allá de la guerra y en procura de lograr un desarrollo integral de la región y de las personas. El reconocimiento internacional del país por su vocación pacifista, también se denota cuando se le otorga el Premio Nobel al Presidente Oscar Arias Sánchez.

Las décadas siguientes hasta hoy están marcadas por los argumentos del discurso penal de guerra proveniente de los EE.UU. Estos son aplicados al combate contra las drogas y a la guerra contra el terrorismo. El convencimiento de los costarricenses acerca del desarme, lleva a atenuar el impacto de tal discurso, toda vez que parafraseando a un autor, esas no son guerras como tales (Hobsbawm, 2008: 169).

\section{Conclusiones}

El ejército juega un importante papel en la temprana conformación del Estado nacional en Costa Rica durante el siglo XIX. A diferencia de lo que ocurre en Panamá y Nicaragua, su creación y el diseño de su misión no responden a imposiciones de los Estados Unidos de América y, contrariamente, a lo que supone cierta historiografía "civilista", durante los primeros tres lustros del siglo XX es todavía una institución robusta que detenta cuotas de poder político relevantes.

La preponderancia del factor geopolítico en las relaciones de los Estados Unidos de América con Costa Rica y sus dos inmediatos vecinos, se ve potenciada por el estallido de la Primera Guerra al comienzo del período, por la Segunda Guerra Mundial y por la Guerra Fría al final del mismo.

La declinación de la importancia política del ejército en Costa Rica y su progresiva conversión en policía, durante el siglo XX, tiene que ver con una constatación cruda y simple: a partir de la apertura del canal de Panamá y la presencia militar norteamericana al norte y al sur de sus fronteras; la institución castrense no sólo está imposibilitada de ejercer la función de defensa externa, sino que le está vedada toda pretensión de participar en las luchas internas por el poder de las clases dirigentes.

La declinación es el resultado de la inhibición de las funciones de defensa de la seguridad interna y externa, como consecuencia de dos sucesivas y contundentes 
demostraciones de fuerza de los Estados Unidos de América: el no reconocimiento del gobierno de facto del General Tinoco, hecho que precipitó su caída y las acciones intimidatorias para impedir la solución militar al conflicto fronterizo entre Costa Rica y Panamá (1921).

La renuncia constitucional al Ejército no implica que hacia 1949 se perciba la paz como un imperativo categórico. No se trata de una renuncia absoluta e incondicional a las armas, sino simplemente de privar a los Estados Unidos de América y a eventuales aliados internos de cualquier posibilidad o pretexto para intervenir militarmente e impedir las reformas impulsadas por Figueres y sus seguidores. Ni los adversarios de Figueres, dentro y fuera del bando vencedor en la guerra civil, ni el propio Figueres descartan el uso de las armas. Prueba de ello es el alzamiento de Cardona en 1949, la invasión desde Nicaragua en 1955 y la existencia de un grupo paramilitar: el MCRL.

La militarización de América Latina y, especialmente, el espectáculo de las dictaduras militares de Centroamérica y el Caribe, generan en Costa Rica un clima progresivo de aversión y rechazo al militarismo y permiten el desarrollo de una opinión pública permeada por valores civilistas y con gran apego al Estado Social de Derecho.

El Presidente Monge Álvarez (1982-1986) al llegar al poder encuentra que los estrategas norteamericanos visualizan la micro-región canalera como parte de un espacio geopolítico mayor: Centroamérica y la Cuenca del Caribe y dentro de este espacio más vasto, resulta potenciado el objetivo político militar de derribar al nuevo gobierno sandinista.

La importancia estratégica de la frontera norte de Costa Rica se incrementa y de esta circunstancia se vale el Gobierno también para remontar la intensa crisis económica, sólo que de una forma muy particular, esto es hipotecando cuotas importantes de soberanía bajo el pretexto de contribuir a la defensa de la democracia.

Si bien la Administración Monge está dispuesta a moderar sus expectativas de soberanía, no muestra la misma inclinación para asumir los riesgos que implica el paso de la Guerra de Baja Intensidad a una guerra abierta. Por eso en un intento deliberado de eliminar tal posibilidad, toma la decisión, considerada por muchos como absurda y contradictoria, de proclamar la Neutralidad Perpetua, Activa y no Armada.

El Presidente Oscar Arias (1986-1990) toma nota de la erosión de la soberanía nacional y del riesgo de que los Estados Unidos de América arrastre a Costa Rica a un enfrentamiento abierto con Nicaragua. Es por eso que aprovechando el descrédito de la política exterior de Reagan por el escándalo Irán-Contra y el clima favorable generado por Contadora y su grupo de apoyo, toma la iniciativa de impulsar un Plan de Paz bajo la consigna "ni una segunda Cuba ni un nuevo Vietnam".

Este Plan constituye un significativo avance en la construcción de la paz regional porque beneficia a toda Centroamérica y no únicamente la micro-región canalera. En lo que concierne a esta última subregión, el Plan implica el ejercer una fuerte presión para revertir el proceso socialista en Nicaragua y, paralelamente, persuadir a los Estados Unidos de América de retirar el apoyo económico y militar que brinda 
a los contrarrevolucionarios nicaragüenses, acantonados tras las rayas fronterizas de los países vecinos. Es precisamente la consecución de ambos objetivos la que obliga a centro-americanizar la solución del conflicto, como una manera de lograr que sus resultados puedan ser posteriormente avalados por los Estados Unidos.

Más relevante que la dimensión espacial de este plan es su amplitud y riqueza conceptual. De manera deliberada rechaza la concepción estrecha de la paz simplemente como ausencia de guerra, y enmarca el concepto dentro de los lineamientos del desarrollo humano y lo asocia, por consiguiente, con el respeto a la democracia, los derechos humanos, la soberanía nacional y el principio de no intervención. Así con una democracia desarmada es como Costa Rica está hoy mejor preparada para resistir las recurrentes presiones geopolíticas que a lo largo de su historia la han obligado a optar entre seguridad y soberanía.

\section{Referencias bibliográficas}

ALVAREZ, M. (2013).Costa Rica y el atentado de la Penca (1984). En Dialogos. Revista de Historia. Vol. 13.No 2. Setiembre 2012- febrero. p. 73-97.

BOWMAN, D. (2000). “¿Fue el compromiso y el consenso de las élites lo que llevó a la democracia en Costa Rica? Evidencia de la década de 1950". En Revista de Historia No 41. EUNA y Editorial Universidad de Costa Rica, enero-junio. p. 91-12.

BOTEY, A. (2012). Infancia, alimentación y filantropía en Costa Rica: La gota de leche (1913). En DÍAZ, D. (2012). Historia de la infancia en la Costa Rica del siglo XX. Aproximaciones. San José. Editorial Nuevas Perspectivas.

CASAS, K. (Compilador) (1997). Relaciones cívico-militares comparadas. Entendiendo los mecanismos de control civil en pequeñas democracias (A.L.). San José, Costa Rica. Fundación Arias para la Paz y el Progreso.

CASCANTE, C. (2012). Entre la Política Exterior y la Política Interna. De la Proclama de la Neutralidad al Plan de Paz (1983-1984). En Diálogos. Revista de Historia. Vol. 13. No 1. Febrero-agosto. p. 3-31.

COSTA RICA.M. 2004. Abolición del Ejército en Costa Rica /Compilador. Biblioteca Nacional Miguel Obregón Lizano.

FEAVER, P. (1997). "El control civil en democracias pequeñas: La contribución de la ciencia política. En CASAS, K. (Copilador) (1997). Relaciones cívico-militares comparadas. Entendiendo los mecanismos de control civil en pequeñas democracias (A.L.). San José, Rica. Fundación Arias para la Paz y el Progreso, p. 67.

HOBSBAWM, E. (2008). Guerra paz en el siglo XXI. Barcelona. Edit. Crítica.

MOLINA, I. 2007. Anticomunismo reformista, competencia electoral y cuestión social en Costa Rica 1931-1948. San José. Editorial Costa Rica.

(1999). Urnas de lo inesperado: fraude electoral y luchas políticas en Costa Rica: 1901-1948/Iván Molina, Fabrice Lehoucq. San José. Editorial Costa Rica.

STEVEN, P. (2007).Historia de Costa Rica: breve, actualizada y con ilustraciones. 2. ed.rev. San José, Costa Rica. Editorial UCR. 
MORALES, M.; ROMERO, R. (2000). La cuestión fronteriza: Costa Rica, Nicaragua y Panamá. Crisis del Estado nacional hacia el siglo XXI. Edit. UNA. Heredia, Costa Rica.

MUÑOZ, M. (1990). El estado y la abolición del Ejército. 1914-1949. San José, Costa Rica. Editorial Porvenir.

(1994). La seguridad de Costa Rica hoy. En SOLIS, L.G.; ROJAS, F. (Editores). De la guerra a la integración: La transición y la seguridad en Centroamérica. San José. Fundación Arias para la Paz y el Progreso y FLACSO-Chile. 1994.

ROMERO, R. (1991). El dilema del Estado costarricense: Seguridad nacional o soberanía. En KRUIJT, D.; TORRES-RIVAS, E. (Coordinadores). América Latina: militares y sociedad. T. I. San José. FLACSO.

"La asamblea nacional constituyente 1949: El discurso anticomunista y la inconstitucionalización del partido Vanguardia Popular". En Diálogos. Revista Electrónica de Historia. ISSN 1401-469 x Vol. 9. No1. 2008. Recuperado de http: historia.fcs.ucr.ac.cr/dialogos.htm

MURILLO, H. (1978). Tinoco y los Estados Unidos. Génesis y caída de un régimen. UNED. San José.

RICHARD, K. 1997. "Los fundamentos olvidados del control civil sobre los militares en gobiernos democráticos”. En CASAS, K. (1997). Relaciones cívico-militares comparadas. Entendiendo los mecanismos de control civil en pequeñas democracias (A.L.). San José, Costa Rica. Fundación Arias para la Paz y el Progreso, p. 39.

ROJAS, F. (2008). "El riesgo de la superposición entre las políticas de defensa y seguridad". En Revista: Nueva Sociedad. No.213. enero-febrero, 36-4.

ROUQUIÉ, A. (1994). Guerras y Paz en América Central. México. Fondo de Cultura Económica.

SAXE-FERNÁNDEZ, J. (1971). Proyecciones hemisféricas de la pax americana. Argentina. Amorrotu editores.

VEGA, J. L. (1981). Orden y progreso. La formación del Estado nacional en Costa Rica. Costa Rica. Editores.

VERGARA, R. et al (1987). Centroamérica. La Guerra de Baja Intensidad. San José. DEI. Periódico. La Tribuna. 01-02-31, p. 6.

\section{La autora}

Mercedes Muñoz Guillén es Máster en Historia por la Universidad de Costa Rica. Especialista en temas de Seguridad del Estado Costarricense y de Centroamérica. Profesora invitada de la Universidad Complutense de Madrid, de la Universidad de Salamanca y del Instituto de Estudios Políticos de Grenoble, Francia. Ocupó diferentes puestos en la Universidad de Costa Rica: Decana de la Facultad de Ciencias Sociales, Directora de la Escuela de Historia, Subdirectora del Centro de Investigaciones Históricas y Subdirectora de la Oficina de Asuntos Internacionales y Cooperación Externa. 